Bol. Acad. peru. leng. 57. 2014 (81-97)

\title{
LA POESÍA IMANTADA DE CÉSAR VALLEJO
}

\author{
LA POÉSIE AIMANTÉE DE CÉSAR VALLEJO
}

\section{CÉSAR VALLEJO’S MAGNETIC POETRY}

\author{
Marco Martos Carrera \\ Academia Peruana de la Lengua
}

\begin{abstract}
Resumen:
El artículo repasa todo el recorrido literario de César Vallejo en el campo de la poesía, repasa su relación con el modernismo y señala cómo se convirtió en el portaestandarte de la vanguardia en lengua española hasta alcanzar la más profunda originalidad en la tradición hispanoamericana.
\end{abstract}

\section{Résumé:}

L'article retrace tout le parcours littéraire de César Vallejo dans le domaine de la poésie, examine son rapport au modernisme et montre comment il est devenu le porte-drapeau de l'avant-garde en langue espagnole, jusqu'à parvenir à la plus profonde originalité dans la tradition hispanoaméricaine.

\section{Abstract:}

The article reviews all the literary career of César Vallejo in the field of poetry. It also revises his relationship with modernism and points 
out how he became the standard-bearer at the forefront of the Spanish language up to reach the deepest originality in Latin American tradition.

Palabras clave: Vallejo; poesía peruana; modernismo; vanguardia.

Mots clés: Vallejo; poésie péruvienne; modernisme; avant-garde.

Key words: Vallejo; Peruvian poetry; modernism; forefront.

Fecha de recepción: $\quad$ 24/02/2014

Fecha de aceptación: $\quad$ 23/04/2014

Las tradiciones literarias en distintos idiomas se consolidan con el paso del tiempo. Cuando César Vallejo (1892-1938) empezó a escribir, el español tenía ya nueve siglos de existencia y podía exhibir figuras individuales de relieve mundial como Cervantes, Góngora, Lope de Vega, San Juan de la Cruz, Quevedo. En tierras peruanas había nacido el Inca Garcilaso de la Vega (1539-1616), dueño de una magnífica prosa de raigambre renacentista, pero no habíamos tenido otro escritor de envergadura que estuviese a la altura de los clásicos peninsulares. Vallejo llegó a llenar esa carencia y lo hizo con un brillo y una potencia inusitados, tanto que su poesía está considerada como la más original de la lengua desde los siglos de oro y su nombre es pronunciado con respeto al lado de los poetas más reputados de la tradición occidental, desde Homero y Virgilio, hasta Dante, Baudelaire, Rimbaud y Mallarmé.

En sus años de formación, en Trujillo, Vallejo tuvo la fortuna de encontrarse con amigos excepcionales, que a su vez recibieron su influencia benéfica, entre ellos Antenor Orrego, el primer crítico que vislumbró la gran calidad de la poesía del vate, Víctor Raúl Haya de la Torre, de importante presencia en la política peruana del siglo xx, José Eulogio Garrido, fino prosista de vena lírica y destacado periodista, Alcides Spelucín, valioso poeta de acentos personales, cantor del mar y de los paisajes de la costa, Juan Espejo Asturrizaga, más tarde biógrafo del propio 
César Vallejo, Óscar Imaña, jurista y poeta. En cierto sentido esa etapa culminó con la publicación de Los heraldos negros en 1919. Para efectos técnicos el libro debe ser considerado como aparecido en 1918, pues así figura en las páginas iniciales, aunque en verdad empezó a circular en julio de 1919. Ocurrió que Vallejo había pedido en 1918 un prólogo a Abraham Valdelomar y este, enfrascado en sus presentaciones públicas en buena parte del territorio del Perú, descuidó la tarea que le había sido encomendada. El poeta esperó un tiempo prudencial y luego lanzó la publicación sin las palabras solicitadas. Este hecho, nimio en el fondo, dada la fama actual de Vallejo, ha confundido a algunos críticos que han buscado comentarios al libro en publicaciones de 1918, sin hallarlos, obviamente. El libro fue lo más novedoso ocurrido en poesía hispanoamericana en esos años; aunque fuera lo único que hubiese publicado César Vallejo, su aparición es motivo suficiente para incorporarlo como algo excepcional en la tradición de la poesía escrita en español. La popularidad del texto no ha menguado con el paso del tiempo, antes por el contrario, una de sus páginas, la que abre el volumen y repite el título que ha hecho famoso a todo el libro, es el poema más conocido y repetido de todos los que escribió el vate. En esos años, en toda la poesía española e hispanoamericana, el poeta más conocido y original era Rubén Darío. Debemos a su pluma legendaria un verdadero avance de la poesía; vinculado profundamente a la tradición, el vate nicaragüense traía a la lírica una apetencia de lejanías, el deseo de cantar a lo distante y aparentemente desconocido y al mismo tiempo a la tierra americana; conocedor profundo de la tradición parnasiana y simbolista, manejaba el verso español con maestría inigualable con acentos musicales nunca vistos; su poesía más duradera es, sin embargo, aquella en la que se despoja de las galas que tan bien conocía y se interna en los meandros del propio sentimiento, de la íntima congoja. En el Perú se escuchaban otras voces que son complementarias a la de Darío, principalmente la de José Santos Chocano, Manuel González Prada, José María Eguren y Abraham Valdelomar. De ellos, el innovador había sido González Prada que cumplió en el Perú el papel que Garcilaso de la Vega en las letras españolas; incorporar ritmos de otras lenguas y tocar temas propios con hondura y originalidad. Sin embargo, el poeta más reconocido no era González Prada, ese papel lo jugaba José Santos Chocano, fino versificador, dueño de un oído notable y de versos rotundos y musicales; vinculado a 
las esferas gobernantes de varios países, fue un poeta oficial en el Perú, sus naturales dotes hicieron el resto: su popularidad era desbordante y en 1922 fue coronado como poeta por el propio presidente de la República Augusto B. Leguía. El canon de la poesía tiene sus curiosidades, José María Eguren, leído en su momento por escasas minorías, junta hoy su nombre al de Vallejo, pues ambos se han convertido en los poetas más reconocidos en nuestra tradición contemporánea. Eguren traía un verso corto, una imaginación prodigiosa, una capacidad de construir universos paralelos al llamado mundo real; en la entrelínea su poesía es profundamente peruana y limeña. Muchos creen reconocer la neblina de la costa peruana en sus poemas, la ambigua luz de nuestros atardeceres, las sombras de nuestras noches más oscuras, los fantasmas que deambulan por las casas y castillos de otros tiempos, las batallas más soñadas que realizadas. Y también el humor de los personajes que esconden en los versos como en desvanes olvidados. En este panorama, Vallejo llegó como un rayo.

La poesía de Los heraldos negros fue bien acogida en su momento principalmente porque la música de sus versos les parecía a los lectores conocida, aquella del modernismo de Rubén Darío. Vallejo se mostraba como un hábil versificador y no cabe ninguna duda de que las versiones iniciales de varios de los poemas estaban muy cercanas a la estética en boga en esos años, sílabas bien contadas, en algunos casos versos alejandrinos o endecasílabos o heptasílabos, la elección de algunas frases o de palabras corrobora esa presunción: "bárbaros Atilas", "Bizancio", son vocablos del santoral modernista, aquella necesidad de lejanía del primer Darío y de sus congéneres. Pero la originalidad del libro no está ni en su versificación, ni en su a ratos exquisito vocabulario, radica en la actitud. Vallejo, como ningún otro poeta hispanoamericano de aquellos años, se atrevía a expresar algo diferente; su sensibilidad sintonizaba mejor con el tiempo que se vivía y se relacionaba directamente con algunos temas universales, tanto que hay un manojo de poemas del texto que todavía hoy merecen estar en la antología más exigente de la poesía hispanoamericana. Vallejo fue más adelante que otros poetas que admiraba como Leopoldo Lugones y José Herrera y Reissig, argentino y uruguayo respectivamente, que se atrevían a incorporar temas cotidianos a sus versos. En uno de sus poemas más célebres, José Herrera y Ressig, describe un oficio religioso en una capilla de pueblo y 
súbito, por la puerta abierta de par en par, ingresa un cortejo: una gallina con sus pollitos. La absoluta originalidad de Vallejo está en su entronque con temas sustanciales a la especie: la naturaleza irracional del dolor, algo que conocen por experiencia propia todos los hombres. La comprobación escueta, directa, de que "hay golpes en la vida tan fuertes como el odio de Dios", la idea de que él mismo había nacido "un día que Dios estuvo enfermo, grave". Sobre estas afirmaciones, que son dos pilares de palabras que empiezan y terminan el libro, se desarrolla toda la poesía que nos ofreció en ese momento. Lo común a la especie es el dolor, lo inesperado de su aparición, su naturaleza perversa. Vallejo siente que la creación misma es producto de un Dios con sus facultades disminuidas, enfermo, grave. El llamado "valle de lágrimas" cristiano, el lugar donde habita el ser humano, la tierra entera, tiene un origen divino, algo está mal en el propio Dios que lo hace crear a seres hechos para el sufrimiento. El otro gran tema que se vincula con el dolor es el la deidad misma. La actitud del poeta frente a Dios es cambiante e incluso contradictoria: cuando la divinidad es evocada como fuente de poder recibe fuertes críticas, explícitas o implícitas del novel autor, pero hay otros textos en los que Dios es visto con ojos menos sombríos, más bien cordiales y amistosos, "porque debe dolerle mucho el corazón.". Otro gran tema de Los heraldos negros es la vida familiar. Vallejo tiene una profunda relación con su entorno familiar, el padre, la madre, los hermanos. Los poemas que dedica a la celebración de ese círculo íntimo están entre los mejores salidos de su pluma. El otro asunto del que queda un variado testimonio es la relación amorosa entre hombre y mujer. Es sabido que tal tipo de atracción tiene componentes espirituales y otros estrictamente carnales: la apetencia de poseer a la persona amada. Vallejo, en unos pocos poemas, pone en evidencia una situación social que se vivía en la época: la educación católica que había recibido le obligaba a idealizar a la mujer amada y a postergar las apetencias sexuales, amparadas por la Biblia dentro del matrimonio. Eso en el aspecto teórico, en la práctica, Vallejo no sabe cómo resolver esa contradicción. Así ocurre en el texto "El poeta a su amada" donde le dice a la mujer que ella se ha crucificado sobre los dos maderos curvados de su beso y atina a soñar en un amor más allá de la muerte, donde ambos dormirán en una sepultura como dos hermanitos. En otros poemas, Vallejo idealiza a la mujer y dice que a ella van sus ojos como polluelos al grano. Esta imagen, hermosa, tierna y alimenticia, si cabe, encierra muy 
finamente una fantasía que los psicólogos remontan a la primera infancia: la idea de alimentarse con lo que se ama. Vallejo es muy fino también cuando evoca un idilio muerto. Ese poema, célebre sin duda, de profunda raigambre lírica, puesto que se refiere a una situación del pasado, en cierto sentido protege a Vallejo de la contradicción que vivía: una muchacha de la que está separado por el tiempo y la distancia, no hace peligrar ni las convicciones cristianas ni los niveles profundos de idealización. En cierto sentido, esa muchacha, Rita, es un equivalente de Beatriz, la amada de Dante, que fue querida por el vate italiano más allá de la muerte. Vallejo utiliza a lo largo de todo el poemario el español del Perú, con un profundo conocimiento de la morfología y la sintaxis, con un vocabulario variado y rico en el que palabras de raigambre castellana se alternan con voces y giros propios del Perú. Ese libro, como todos sus escritos posteriores, es una rica fuente para encontrar peruanismos y americanismos. Nuestros lexicógrafos tienen ahí un abundante material de trabajo ${ }^{1}$.

La aparición de Trilce en 1922, convierte, según ahora mismo se puede advertir, a Vallejo en el poeta más importante de la lengua. Su propia vida había marchado muy rápida y estaba llena de contradicciones. Acusado sin pruebas de incendiario en su pueblo natal, Santiago de Chuco, es probablemente en la cárcel de Trujillo donde empieza a

1 Un caso curioso de discusión literaria se produce en el poema $i . . . . . .$. de la sección "De la tierra"

que empieza:

- Si te amara, qué sería?

-Una orgía.

-Y si él te amara

Sería

todo rituario pero menos dulce.

Así figura el texto en la mayor parte de las ediciones, pero el suscrito, junto con Max Silva, cotejado diversos ejemplares, hasta seis de la edición príncipe, encontramos tres con otra escritura. El verso quinto dice: "todo de rito, pero menos dulce". La explicación a tal hecho puede encontrarse en la costumbre, perdida felizmente ahora, de hacer cambios ocasionales en los textos "de última hora". Sin duda se trata de un cambio menor y de escasa importancia, pero curioso, y por eso dejamos aquí constancia. Los versos no mejoran ni empeoran con ese cambio. 
pergeñar esos versos insólitos. Si en la época de Los heraldos negros, el poeta parece insular, a pesar de las obvias relaciones con el modernismo, tanto que la semejanza con los poetas expresionistas como Georg Trakl, descubierta recién, no pasa de ser una asombrosa coincidencia, puesto que no hay forma de precisar cómo Vallejo, sin conocer el alemán, ni las traducciones respectivas, pudo acercarse a esos poetas; nuestro vate muestra en este nuevo libro una originalidad radical. Han tenido que pasar muchos años para que esta opinión se abra paso y se convierta en consenso. En esa época en Europa y en toda América se sucedían los movimientos de vanguardia. Mallarmé había señalado en 1897 que la poesía durante mucho tiempo se había asociado a la música y que era hora de vincularla a otros artes. Puesto que lo hizo, relacionando sus poemas finales con las artes gráficas, no cabe sino considerarlo como un precursor de las vanguardias. Estas florecieron en las primeras décadas del siglo xx. No cuestionaron solamente los aspectos formales sino que exigen un cambio de actitud. A fines del siglo XIx, las sociedades europeas habían vivido la ilusión del progreso sin fin que se iniciaba. Los albores del nuevo siglo, junto con descubrimientos importantes como el cinematógrafo, la teoría de la relatividad de Eistein, el automóvil, sembraron en los espíritus una desazón; si Baudelaire en el siglo XIX, había postulado apartarse de la multitud, los poetas de vanguardia ensayan otras actitudes frente a los tiempos sombríos, el que penetró con más hondura en esos abismos fue Georg Trakl, su verso suave y fluido expresa las grietas del corazón, el sufrimiento sin remedio de quien se siente excluido. Que haya sido farmacéutico, combatiente en la primera guerra mundial y que haya muerto por una dosis excesiva de cocaína no son sino datos complementarios que corroboran el desamparo, el desasosiego, la inquietud, la zozobra de los espíritus europeos más sensibles de aquellos años. Hubo por cierto otras formas de reaccionar frente al nuevo siglo, algunos como Marinetti y sus futuristas asociaron su presente literario a lo que parecía el futuro: la admiración sin medida de las conquistas tecnológicas: un automóvil de carreras les parecía más hermoso que la Venus de Samotracia. Junto a los futuristas italianos, apareció el movimiento Dadá de Tristán Tazra que postulaba la poesía como espectáculo y sin embargo dinamitaba desde dentro la posibilidad de la comunicación poética. Vallejo fue más allá que todos ellos y puede 
decirse que Trilce es el libro más original de aquellos años en la lengua española. Como sus congéneres europeos, Vallejo admite la importancia de lo intuitivo y deja a un costado la alta consciencia literaria que bien conocía pues había frecuentado los modelos modernistas. El texto tenía una visión local, provinciana y nacional y contrastaba con el cosmopolitismo propio de los modernistas, se situaba en un presente y dejaba de lado las influencias parnasianas y simbolistas que habían marcado las primeras producciones del aeda. Vallejo expresaba, como nadie lo había hecho, el dolor en sus íntimas esferas: la del individuo arrojado en las mazmorras. Lo primero que siente el lector que enfrenta a esos poemas es extrañeza. Los poemas son diferentes a otros leídos de cualquier autor. En ese sentido, en aquel año de 1922, ningún autor de poesía hispanoamericana era más diferente. Es cierto que la vanguardia estaba instalada en América y tenía varios lugares en los que hacía fortuna: en México estaban los estridentistas de Maples Arce, en Chile los creacionistas de Vicente Huidobro y había una pujante vanguardia en distintos puntos del continente, pero Vallejo, él solo, representa genuinamente la vanguardia en el Perú. La importancia de Trilce para nuestra lengua ha sido comparada por Roberto Fernández Retamar a la que tienen La tierra baldía de T.S. Eliot y Ulises de James Joyce para la lengua inglesa y $A$ la sombra de las muchachas en flor de Marcel Proust para la lengua francesa. La dificultad de Trilce no radica en su vocabulario de amplio registro que amalgama expresiones cultivadas contemporáneas, con arcaísmos de prosapia castellana y con abundantes expresiones cotidianas del léxico familiar, está en el romper puentes con lo esperado. En su laboratorio verbal, el poeta siempre está diciendo otra cosa. No hay libro de poesía en español que haya merecido tantos comentarios e interpretaciones pues el texto fascina a quien abreva en sus páginas y el lector siente que tiene que poner mucho de sí para intentar comprenderlo. Como es entendible, un volumen así ha suscitado verdaderas batallas verbales entre los críticos que a veces han perdido la brújula al comentar posiciones diversas a la suya. En esos poemas, sin modelo conocido, Vallejo maneja los tiempos reales, presente, pasado y futuro, como en los sueños sin sucesión lineal. El futuro influye en el pasado y el pasado parece presente y el presente se diluye en cada una de las líneas. Vallejo escribe en una especie de presente eterno. El poeta dominicano Manuel del Cabral, sostuvo en Lima, en 
1986, en una entrevista personal, que la diferencia entre Vallejo y otros poetas es que nuestro escritor en su dicción expresa con intensidad la condición más elemental del hombre: su animalidad. Podemos percibir en los poemas de cárcel, en los de sufrimiento amoroso, en los intensos poemas existenciales que se adelantan a la dicción de Gottfried Benn en décadas siguientes, algo elemental pero profundo: un dolor que va más allá de lo imaginado, un tocar fondo en la experiencia de los hombres. Lo que no sabemos es la naturaleza de ese dolor y, por último, su origen, aunque se le juntaron varias desdichas: la prisión, la muerte de su madre y la separación amorosa de Otilia Villanueva, su musa de aquellos años. El sufrimiento sería una de las marcas que Vallejo desarrollará en su poesía posterior. Lo mejor que se ha dicho en el terreno de la composición literaria de Trilce son las palabras prologales de Antenor Orrego: "César Vallejo está destripando los muñecos de la retórica. Los ha destripado ya”.

A su muerte, el 15 de abril de 1938, Vallejo, que había desarrollado una fecunda tarea literaria escribiendo cuentos, novelas, obras de teatro, reportajes, dejó un conjunto de poemas sin título general, excepto un manojo de textos sobre la guerra civil española. Raúl Porras y Georgette Vallejo publicaron dichos textos bajo el título de Poemas humanos en 1939. Es cierto que Vallejo, en una lista de títulos posibles había colocado entre una docena más el de Libro de poemas bumanos que contrastaba con el título Versos divinos del poeta español Gerardo Diego, pero no queda ninguna señal clara y rotunda de su voluntad. Por eso, en esto también difieren los críticos. Algunos como Américo Ferrari llaman a estos poemas Poemas de París, otros, los más numerosos, siguiendo las opiniones de Georgette Vallejo, hacen una división de Poemas en prosa, Poemas humanos, España aparta de mí este cáliz. Esta última porción sí la dejó ordenada César Vallejo y fue publicada también en 1939 en España. Hay otros críticos, por último, que prefieren llamar a todas estas páginas Poemas póstumos. Es el caso de Ricardo Silva Santisteban y de Antonio Merino. En verdad, es posible inclinarse por una u otra posición, sin caer en las posiciones aleatorias de Juan Larrea que creía poder ordenar los poemas siguiendo el color de la cinta de la máquina de escribir del poeta y de ciertas marcas que este ponía en cada uno de sus textos corregidos una y otra vez, como puede en los originales conservados en Lima en la Clínica 
San Juan de Dios, por expresa voluntad de Georgette Vallejo. Dante no colocó el nombre de Divina comedia a su libro más famoso y puede decirse que lo mismo ocurre con Vallejo. El nombre de Poemas humanos a la porción más numerosa de sus poemas póstumos se ha impuesto y arrastra por lo tanto una clara división, tal como figura en la mayoría de las ediciones actuales. Es la que se ha seguido en esta edición preparada por Carlos Garayar para la editorial Peisa.

En esta fase final de su escritura, Vallejo tiene logros notables, es sin duda, la porción más madura de su producción. En su corto libro sobre España, que alcanzó a redondear, Vallejo logra acentos épicos que ya no se presentaban en la poesía contemporánea. Sin duda, los poemas tienen una fuerza política: la identificación con el bando republicano en la guerra civil española, pero eso no explica su encanto y su poder. Esos catorce poemas resultan imperecederos por la potencia afectiva, la identificación con los que sufren combatiendo, la idea de que cada ser humano, siendo diferente, tiene los afectos, la inteligencia, la posibilidad de tener alegría y sufrir dolor, semejantes en todos sus congéneres. Vallejo convirtió a España en un símbolo. Lo más interesante del texto es que a más de siete décadas de su escritura sigue pareciendo hermoso a quien lo lea, lo que quiere decir que Vallejo logró la síntesis perfecta. En el tiempo de su escritura los poemas sirvieron, sin duda, a la causa republicana, leídos ahora por personas que ignoran los detalles de esa cruenta guerra civil, queda límpida la idea de la solidaridad en medio de los sufrimientos, la posibilidad simbólica de vencer a la propia muerte. En literatura, probablemente son las páginas más intensas escritas sobre un conflicto armado en el siglo xx.

En toda su etapa parisina Vallejo conoció el dolor de un modo inédito, hasta el punto de considerarlo lo más característico del ser humano:

Yo no sufro de ese dolor como César Vallejo. Yo me duelo ahora como artista, ni como hombre, ni como ser vivo siquiera. Yo no sufro de este dolor como hombre ni como simple ser vivo siquiera. Yo no sufro de este dolor como católico, como mahometano ni como ateo. Hoy sufro solamente. Si no me llamase César Vallejo, 
también sufriría este mismo dolor. Si no fuese artista también lo sufrivía. Si no fuese hombre, ni ser vivo siquiera, también lo sufriría. Si no fuese católico, ni ateo. Ni mahometano, también lo sufriría. Hoy sufro desde más abajo. Hoy sufro solamente. [...] escribió en el texto Voy a hablar de la esperanza que figura en Poemas en prosa.

En Poemas humanos el vate deja atrás la etapa experimental de Trilce. En cierto sentido Vallejo retorna al cauce general de la poesía que, viniendo del romanticismo, simbolismo, parnasianismo, pone entre paréntesis a la misma vanguardia o, mejor, la tiene asimilada. Todo lo hace con una profunda originalidad. Tanto que su escritura puede distinguirse entre muchas. En 1925, un escritor peruano poco conocido, Clodoaldo Espinoza Soto había dicho: "Vallejo hará escuela y será el vallejismo" y si bien eso no es una verdad literal, sí lo es en su sentido más hondo y legítimo. Poetas de gran calidad como Thomas Merton en Estados Unidos, o como Gonzalo Rojas en Chile, o como Alejandro Romualdo y Wáshington Delgado en el Perú, o Félix Grande en España, han reconocido su calidad y le rinden pleitesía como maestro. En estos versos, con una rara intensidad, Vallejo expresa su amor por el Perú. En ese sentido sus poemas "Telúrica y magnética" o "Fue domingo en las claras orejas de mi burro" son ejemplares. En un mismo texto Vallejo tiende puentes al lector sin experiencia literaria y al mismo tiempo se dirige al más cultivado y diligente. Un buen ejemplo de lo dicho es su poema "Piedra negra sobre piedra blanca", un soneto en sus orígenes, que puede ser leído de diversos modos no contradictorios. Algunos pueden encontrar la hipertrofia del yo romántico, ese situarse del "yo creador" en un centro pequeño, apartado del mundo, otros pueden advertir la "vocación de apaleado" de Vallejo que tiene literariamente un origen romántico y personalmente la huella del sufrimiento personal del vate, o puede singularizarse la reflexión metafísica sobre la condición humana o, por último, el lector puede regocijarse con la perfección de la forma. Todas estas cualidades sumadas, dan el éxito sostenido del poema, uno de los más célebres de Vallejo. En Poemas humanos los textos se potencian unos a otros. Viviendo en París el poeta experimenta la soledad y el sufrimiento de la mayoría en las grandes urbes. En pocos versos lo expresa de la manera más clara que en las líneas finales de "La rueda del hambriento": 


\section{$[\ldots]$}

Un pedazo de pan ¿tampoco habrá ahora para mí?

Ya no más he de ser lo que siempre he de ser, pero dadme una piedra en qué sentarme, pero dadme, por favor, un pedazo de pan en qué sentarme, pero dadme en español algo, en fin, de beber, de comer, de vivir, de reposarse, y después me iré...

Hallo una extraña forma, esta muy rota y sucia mi camisa y ya no tengo nada, esto es horrendo.

Los medievales sostenían que era necesario vivir primero antes de filosofar. Una de las razones de la permanencia de la poesía de Vallejo en el gusto popular tiene que ver con la identificación emocional del lector con los textos que lee. Vallejo no habla del dolor y del sufrimiento desde un escritorio. Es obvio para quien lo conoce que este ser humano conoce los entresijos de lo horrendo, la interminable sucesión de días teniendo apenas qué comer. La correspondencia con sus amigos da abundante testimonio de esta situación. Pero Vallejo si permanece como un paradigma no es por el sufrimiento, sino por la cristalización de estos padecimientos y de estas angustias en hondos versos que nos parecen verdaderos. Desde el punto de vista de la concepción literaria Vallejo se distanció y mucho, de la estela del surrealismo que preconizaba André Breton. En aquellos años, la teoría psicoanalítica de Freud tenía un auge. El psiquiatra vienés insistía en la importancia del inconsciente en la vida diaria de todos los seres humanos y esto en el terreno literario venía a reforzar las teorías de origen romántico sobre la porosidad del creador a la espera de la inspiración, que a su vez tienen un origen platónico. Un poeta como Rilke, por ejemplo, apela en sus escritos teóricos a la necesidad de que el poeta tenga una vasta experiencia de la vida y que sea capaz de aguardar la chispa creadora que germinará en su corazón. 
Los surrealistas, por lo menos de modo teórico, propiciaron la escritura automática, ese escribir por escribir que va acumulando palabras. Vallejo salió al frente de esta concepción, él, que tenía tantas emociones, que era un poeta de una intuición poderosa, como lo había probado en Trilce, conforme adquiere más experiencia, la definitiva, se aparta no solo del surrealismo, sino de algo que el mismo traía desde su juventud: una raíz romántica. Y esto es tal vez lo más importante que puede decirse hoy de la poesía de Vallejo en su fase final. En ese volumen que llamamos Poemas bumanos, el poeta hace una síntesis de sus modos de poetizar: hay textos de una intensidad afectiva inmensa, verdaderas confesiones en verso, pero hay otros, que son los menos, que anuncian la poesía del porvenir, la llamada poesía objetiva que soñó Rimbaud cuando escribió: "yo es otro”, la voluntad de expresar lo que realmente es. En los mismos años que escribía Vallejo, un discípulo disidente de Freud, Carl Jung, elaboró su teoría en la que insiste en la posibilidad de que exista una conciencia multiplicada, la verdadera conciencia, a la que se puede llegar después de conocer mucho el mundo. Ese "sí mismo" como la llama, tiene la virtud de concentrar la vida inconsciente en la vida consciente, salta la historia o la entrevera en un presente eterno. Aquel que llega a ese "sí mismo" es el sabio de la tribu. Vallejo, que no conocía a Jung, puesto que no aparece estudiado ni citado en sus artículos periodísticos, llega por los misteriosos caminos de la creación literaria a las mismas conclusiones:

¡Cuatro conciencias!

iCuatro conciencias

Simultáneas enrédanse en la mía!

iSi vieráis cómo ese movimiento

apenas cabe ahora en mi conciencia!

¡Es aplastante! Dentro de una bóveda

pueden muy bien

adosarse, ya internas, o ya externas, segundas bóvedas, mas nunca cuartas;

mejor dicho, sí,

más siempre y, a lo sumo, cual segundas.

No puedo concebirlo; es aplastante. 


\begin{abstract}
Vosotros mismos a quienes inicio en la noción de estas cuatro conciencias simultáneas, enredadas en una sola, apenas os tenéis de pie ante mi cuadrúpedo intensivo. Y yo, que le entrevisto (Estoy seguro)!
\end{abstract}

¿Por qué permanece Vallejo en el gusto de las personas en el Perú y el mundo? En primer lugar por el efecto poderoso de su poesía en distintas personas situadas en cualquier parte del globo terráqueo, pero además, también, por la importancia que tiene la educación en distintas partes del mundo. El hecho de que aparezca en los programas escolares es fundamental. Felizmente el Perú por fin le está haciendo justicia, tenemos universidades, avenidas, monumentos, institutos, clubes deportivos que perennizan su nombre y lo vuelven un clásico, uno de aquellos escritores cuya fama nos alcanza antes de leerlo. Han pasado ya las polémicas sobre sus vínculos con el marxismo y con el cristianismo. Existen poderosas razones para decir que este comunista tuvo, como el propio Marx, un aliento cristiano toda su vida. Metafísico hasta lo más hondo, Vallejo quiso, en sus sueños, construir el paraíso en la tierra. Vallejo es el poeta del dolor como se viene diciendo, pero es también el poeta de la esperanza en el hombre y en sus capacidades científicas y afectivas casi infinitas. $Y$ es también el poeta de la solidaridad:
Amado sea el que tiene chinches, el que lleva el zapato roto bajo la lluvia, el que vela el cadáver de un pan con dos cerillas, el que se coge un dedo en una puerta, el que no tiene cumpleaños, el que perdió su sombra en un incendio, el animal, el que parece un loro, el que parece un hombre, el pobre rico, el puro miserable, el pobre pobre!

Decimos que la poesía de Vallejo es imantada porque atrapa a toda persona que se allegue a sus páginas. 


\section{BIBLIOGRAFÍA}

BELLINI, Giuseppe. Historia de la literatura hispanoamericana. Madrid, Castalia, 1990.

CORNEJO POLAR, Antonio. Historia de la literatura del Perú republicano. Lima, Editorial Mejía Baca, 1980.

FRANCO, Jean. Introducción a la literatura hispanoamericana. Caracas, Monte Ávila, 1979.

HENRÍQUEZ UREÑA, Pedro. Historia cultural y literaria de la América Hispánica. Edición de Vicente Cervera Salinas. Madrid, Verbum, 2007.

MARTOS CARRERA, Marco. Poéticas de César Vallejo. Lima, Editorial San Marcos, Academia Peruana de la Lengua, 2013.

. Poéticas de César Vallejo. Lima, Cátedra Vallejo, 2014.

MONGUIÓ, Luis. La poesía post modernista peruana. México, Fondo de Cultura Económica, 1951.

OVIEDO, José Miguel. Historia de la literatura hispanoamericana. De Borges al presente. Tomo 4. Madrid, Alianza Editorial, 2002.

SÁNCHEZ, Luis Alberto. Derrotero para una bistoria cultural del Perú. Sexta edición. Lima, Emisa Editores, 1989.

TAMAYO VARGAS, Augusto. Literatura Peruana. Quinta edición. Lima, Peisa, 1993.

VALLEJO, César. Los heraldos negros. Lima, Souza Ferreira, 1918 (recién circuló en julio de 1919). 
https://doi.org/10.46744/bapl.201401.003

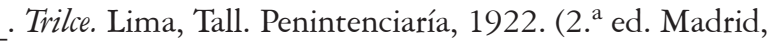
1930).

. Poemas bumanos (1923-1938). París: Presses Modernes au Palais Royal, 1938.

. España, aparta de mí este cális. Ejército del Este, (Monasterio de Montserrat, Barcelona), 1939.

- Obra poética completa. Ed. con facsímiles. Ed. de Georgette de Vallejo. Lima, Francisco Moncloa Edts., 1968.

. Trike. Ed. anotada por Marco Martos y Elsa Villanueva. Lima, Peisa, 1987.

. Poemas en prosa. Poemas humanos. España, aparta de mí este cáliz. Ed. de Julio Vélez. Madrid, Cátedra, 1988.

- Obra poética. Ed. crítica coordinada por Américo Ferrari. París y Madrid, Archivos de la ALLCA, 1988.

. Poesía completa. Ed. crítica de Raúl Hernández Novás. La Habana, Edt. Arte y Literatura y Casa de las Américas, 1988.

- Poesía completa. Ed. con facsímiles anotada por Antonio Merino. Madrid, Akal, 1996.

- Poesía completa. Ed. de Ricardo Silva-Santisteban, con facsímiles y documentación de la recepción en vida de Vallejo. 4 tomos. Lima, Fondo Editorial de la PUCP, 1997.

. Poemas completos. Ed. anotada por Ricardo González Vigil. Lima, Copé (PetroPerú), 1998.

. Autógrafos olvidados. Ed. de Juan Flo y Stephen Hart. Lima, Fondo Editorial de la PUCP, 2003. 
LA POESÍA IMANTADA DE CÉSAR VALLEJO

https://doi.org/10.46744/bapl.201401.003

. Poesía completa. Los heraldos negros. Nueva ed. crítica de Ricardo González Vigil. Trujillo, INC (Universidad Ricardo Palma), 2005.

\section{Correspondencia:}

\section{Marco Martos Carrera}

Presidente de la Academia Peruana de la Lengua.

Correo electrónico: marcomartos9@hotmail.com 